\title{
Changes in beverage consumption in Norwegian children from 2001 to 2008
}

\author{
Tonje H Stea ${ }^{1, *}$, Nina C Øverby ${ }^{1}, K_{\text {Knut-Inge Klepp }}^{2}$ and Elling Bere ${ }^{1}$ \\ 'Department of Public Health, Sport and Nutrition, Faculty of Health and Sport, University of Agder, \\ PO Box 422, 4604 Kristiansand, Norway: ${ }^{2}$ Department of Nutrition, Faculty of Medicine, \\ University of Oslo, Oslo, Norway
}

Submitted 6 June 2010: Accepted 22 June 2011: First published online 11 August 2011

\begin{abstract}
Objective: To analyse (i) differences in beverage pattern among Norwegian children in 2001 and 2008; (ii) beverage intake related to gender, parental education and family composition; and (iii) potential disparities in time trends among the different groups.

Design: Within the Fruits and Vegetables Make the Marks (FVMM) project, 6th and 7 th grade pupils filled in a questionnaire about frequency of beverage intake (times/week) in 2001 and 2008

Setting: Twenty-seven elementary schools in two Norwegian counties.

Subjects: In 2001 a total of 1488 and in 20081339 pupils participated.

Results: Between 2001 and 2008, a decreased consumption frequency of juice (from 3.6 to $3 \cdot 4$ times/week, $P=0 \cdot 012$ ), lemonade (from $4 \cdot 8$ to $2 \cdot 5$ times/week, $P<0 \cdot 001$ ) and regular soft drinks (from $2 \cdot 7$ to 1.6 times/week, $P<0 \cdot 001$ ), but an increased consumption frequency of diet soft drinks (from $1 \cdot 2$ to $1 \cdot 6$ times/week, $P<0 \cdot 001$ ), were observed. From 2001 to 2008, boys increased their frequency of juice consumption (from $3 \cdot 1$ to $3 \cdot 3$ times/week) whereas girls decreased their frequency of juice consumption $(3 \cdot 8$ to $3 \cdot 4$ times/week; interaction time $\times$ gender $P=0 \cdot 02)$. Children with higher educated parents increased their frequency of juice consumption $(3.6$ to 3.8 times/week) whereas those with lower educated parents decreased their frequency of juice consumption $(3 \cdot 3$ to $3 \cdot 0$ times/week; interaction time $\times$ parental education $P=0 \cdot 04$ ).

Conclusion: A lower frequency of consumption of sugar-sweetened beverages was observed among pupils in 2008 than in 2001. This is in accordance with the Norwegian health authority's goals and strategies for this time period, and is an important step to improve the dietary health of adolescents.
\end{abstract}

\author{
Keywords \\ Children \\ Time trends \\ Beverage consumption
}

Norwegian national studies carried out in the period 1997-2001 among children and adolescents showed a high intake of added sugar, with sugar-sweetened beverages (SSB) as a major source ${ }^{(1,2)}$. Boys aged 13 years reported an average daily intake of approximately $500 \mathrm{ml}$ sugar-sweetened soft drinks ${ }^{(3)}$. Another study in 2005 showed that a total of $63 \%$ and $27 \%$ of Norwegian 9th and 10th graders, respectively, reported to drink regular and diet soft drinks twice weekly or more, and $24 \%$ and $8 \%$ reported drinking regular soft drinks and diet soft drinks once weekly or more at school ${ }^{(4)}$. The national dietary survey of Norwegian children and adolescents revealed a negative association between the intake of added sugar and intakes of micronutrients, fruit and vegetables $^{(3)}$. Marshall et al. $^{(5)}$ have also reported that both $100 \%$ juice as well as SSB intakes were negatively associated with adequate intakes of multiple nutrients and overall diet quality. Juice (100\%) has been included in the Norwegian fruit and vegetable recommendation since $1996^{(6)}$; however, a recently published proposal for Norwegian food-based guidelines specifies that only one glass of juice per day is recommended ${ }^{(7)}$.

From the early 2000s to today, there has been an increased focus on the positive association between greater intake of SSB and weight gain and obesity among children and adolescents ${ }^{(8)}$. Previous studies have described that both SSB and fruit juice are associated with an increased risk of tooth decay ${ }^{(9,10)}$. Moreover, in the last 10 years, several studies have shown a positive association between consumption of SSB and weight gain and higher BMI, both in children and teenagers ${ }^{(8,11)}$. Other studies have revealed a positive association, independent of body weight, between consumption of SSB and high blood pressure in adolescents, and the risks for developing type 2 diabetes and CHD later in life ${ }^{(12-14)}$. A recent study by Odegaard et $a l^{(15)}$ reported an increased risk for 
development of type 2 diabetes with a consumption of $\geq 2$ drinks/week, both of SSB and fruit juice.

Several previously published studies have shown that boys tend to drink more soft drinks than girls ${ }^{(16-18)}$, whereas there has been a limited focus on other sociodemographic factors, such as the association between parental education and/or family structure. The Young Hunt study in Norway reported recently that higher level of parental education, in particular the mother's education, was inversely associated with daily soft drinks consumption among both girls and boys ${ }^{(16)}$. Another study showed a positive association between parental education and adolescents' diet, including fruit juice consumption ${ }^{(19)}$.

Recently a number of national health initiatives have begun in Norway in order to reduce the consumption of sugar-sweetened foods and beverages. From 2007 to 2011 the national health authority had a specific goal to reduce the number of people drinking soft drinks and lemonade by $20 \%{ }^{(20)}$. The initiatives to reach this goal have mainly been focusing on structural/environmental changes. In order to accelerate changes in diet and to reduce social inequalities, the Norwegian Consumer Council together with the food industry have published guidelines specifying that the marketing of unhealthy foods aimed at children should be prohibited ${ }^{(21)}$. Norwegian health authorities have also supported the WHO initiative to reduce marketing of unhealthy foods and beverages aimed at children and young people ${ }^{(22)}$. In addition, the state has levied a special tax on non-alcoholic beverages containing added sugar or sweeteners which helps to limit consumption of sugary beverages $^{(23)}$. The tax increased from NOK 1.52 to NOK 1.68 between 2002 and 2008 and to NOK $2 \cdot 76$ in $2010^{(23,24)}$. Further, as a result of the increased focus on reducing intake of added sugar, Norwegian food and beverage manufacturers have been challenged to introduce a number of new products with a reduced content of added sugar over recent years. The Norwegian Directorate of Health has also published recommendations related to school meals, specifying that school owners should prevent access to soft drinks ${ }^{(20)}$. Thus, few Norwegian schools sell soft drinks. Based on the results of a study performed by Bere et al. ${ }^{(4)}$, rules concerning soft drinks consumption at school, not only sales, were suggested to the lower odds for drinking soft drinks at school. In addition, during the last few years the publicity about the potential negative health effects of added sugar has been great, and a decrease in regular soft drinks consumption has been reported between 2001 and 2007 in the general Norwegian population ${ }^{(25)}$.

However, no published studies have reported differences in intake of SSB among adolescents in Norway before and after these initiatives, nor the potential disparities in time trends in different sociodemographic groups. Thus, the objective of the present study was to analyse: (i) differences in intakes of fruit juice, lemonade, regular and diet soft drinks among Norwegian children in 2001 and 2008; (ii) beverage intake related to gender, parental education and family composition; and (iii) potential disparities in time trends among the different groups.

\section{Materials and methods}

\section{Sample and procedure}

The present study is a part of the Fruits and Vegetables Make the Marks (FVMM) project. In 2001 the FVMM collected dietary data among 6th and 7 th grade classes in thirty-eight randomly selected elementary schools from two of Norway's nineteen counties. A new study was conducted in 2008 in which twenty-seven of the original schools participated. During both data collections, the same questionnaire was completed by the children in the presence of a trained project worker in the classroom. One school lesson ( $45 \mathrm{~min}$ ) was used to complete the questionnaire. The present study included 1488 children in 6th and 7 th grade from these twenty-seven Norwegian elementary schools in 2001 and 1339 children in 2008. In total 2827 children participated (out of 3439 eligible; participation rate $82 \cdot 2 \%$ ). The main reason why children did not participate in the study was absence from school on the survey day. Participating children brought home a parent questionnaire to be completed by one of their parents; in the case of 1230 and 996 pupils, respectively, in 2001 and 2008, one of their parents completed this parent questionnaire on behalf of both parents. Informed consent was obtained from parents and children prior to participation in the study. Ethical approval and research clearance were obtained from The Norwegian Social Science Data Services.

The questionnaire included questions concerning habitual beverage consumption, including 'How often do you drink regular soft drinks, diet soft drinks, lemonade and fruit juice?' In Norway, the consumption pattern of syrup and water (called lemonade) is different from the soft drinks pattern in adolescents. Lemonade is usually consumed during the week, and soft drinks during weekends ${ }^{(26)}$. Thus, the consumption of lemonade and soft drinks are analysed separately in the study. All four items had ten response alternatives and were recoded into frequency of consumption per week (never $=0$, less than once weekly $=0 \cdot 5$, once weekly $=1$, twice weekly $=2, \ldots$, six times weekly $=6$, every day $=7$, several times daily $=10$ ). Based on data from a previous test-retest study involving 114 children of 6th grade, individual scores were significantly $(P<0 \cdot 001)$ correlated (Pearson's correlation coefficient) for consumption frequency of juice $(r=0 \cdot 78)$, lemonade $(r=0 \cdot 75)$, regular soft drinks $(r=0 \cdot 72)$ and diet soft drinks $(r=0 \cdot 44)^{(27)}$.

Stewart and Menning ${ }^{(28)}$ have reported that family structure is likely to affect adolescents' eating habits. Adolescents living in non-traditional families were more likely than adolescents living with two biological/adoptive parents to display unhealthy eating habits. Thus, questions regarding gender and number of parents in the household were also registered by the children participating in the present study. 
Number of parents in the household was assessed by 'Tick the alternative showing the persons living at home with you'. Response alternatives were mother, father, stepmother and stepfather. Participants could tick more than one alternative if they lived with two parents. If parents were separated, the participants were supposed to tick the alternative showing the parent with whom they lived with most of the time. All responses were added, and then dichotomized into living with one parent or living with two parents.

Parental educational level was assessed individually in the questionnaire filled in by one of the parents, with one question 'What level of education do you have?' The question had four response alternatives: (i) elementary school; (ii) high school; (iii) college or university (3 years or less); and (iv) college or university (more than 3 years). This variable was dichotomized (lower $=$ no college or university education; higher $=$ having attended college or university) .

\section{Statistical analyses}

To compare beverage intake levels between the 2001 and 2008 cohort we used an independent-samples $t$ test (Table 1). We also used multilevel linear mixed models (Tables 2 and 3) in order to take into account the nested design of the study and adjust for gender, parental education level, the number of parents in the household and time of data collection (2001 or 2008). The models were also adjusted for school as a random effect. In addition, we compared the distribution of the genders, parental education and number of parents in the household between the two cohorts using the $\chi^{2}$ test (Table 1). To assess the overall association between gender, parental education, family composition and beverage consumption, we combined all available data (Table 2). Finally, to explore potential disparities in time trends for beverage consumption between subgroups, we included interaction terms into the multilevel mixed models (Table 3). All multilevel linear mixed models that were used to estimate the associations were adjusted for all variables presented for each model. In addition, assumptions for the multilevel linear mixed models were checked and met. A significant interaction term $(P<0 \cdot 05)$ indicates that the time trend differed between the subgroups. All statistical analyses were performed using the SPSS statistical software package version 16.0 (SPSS Inc., Chicago, IL, USA).

\section{Results}

Table 1 gives a description of the participants and shows that there were no differences in gender or number of parents in the household in 2001 and 2008. About 20\% reported to live with only one parent most of the time.

Table 1 Description of participants included in 2001 and 2008; 6th and 7th grade Norwegian pupils, the Fruits and Vegetables Make the Marks (FVMM) project

\begin{tabular}{|c|c|c|c|}
\hline & 2001 & 2008 & $P$ value ${ }^{*}$ \\
\hline \multicolumn{4}{|l|}{ Gender (\%) } \\
\hline Male & 50 & 48 & \\
\hline Female & 50 & 52 & $0 \cdot 21$ \\
\hline \multicolumn{4}{|c|}{ Parents in household (\%) } \\
\hline 1 & 19 & 20 & \\
\hline$>1$ & 81 & 80 & $0 \cdot 72$ \\
\hline \multicolumn{4}{|c|}{ Parental education (\%) } \\
\hline Low & 58 & 46 & \\
\hline High & 42 & 54 & $<0.001$ \\
\hline \multicolumn{4}{|c|}{ Frequency of beverage consumption (times/week) } \\
\hline \multicolumn{4}{|c|}{ Juice } \\
\hline Mean & $3 \cdot 6$ & $3 \cdot 4$ & $0 \cdot 012$ \\
\hline $95 \% \mathrm{Cl}$ & $3 \cdot 5,3 \cdot 8$ & $3 \cdot 2,3 \cdot 5$ & \\
\hline Median & $3 \cdot 0$ & $3 \cdot 0$ & \\
\hline Q1, Q3 & $1 \cdot 0,3 \cdot 0$ & $1 \cdot 0,5 \cdot 0$ & \\
\hline \multicolumn{4}{|l|}{ Lemonade } \\
\hline Mean & $4 \cdot 8$ & $2 \cdot 5$ & $<0.001$ \\
\hline $95 \% \mathrm{Cl}$ & $4 \cdot 6,4 \cdot 9$ & $2 \cdot 4,2 \cdot 7$ & \\
\hline Median & $5 \cdot 0$ & $2 \cdot 0$ & \\
\hline Q1, Q3 & $3 \cdot 0,7 \cdot 0$ & $0 \cdot 5,4 \cdot 0$ & \\
\hline \multicolumn{4}{|c|}{ Regular soft drinks } \\
\hline Mean & $2 \cdot 7$ & $1 \cdot 6$ & $<0.001$ \\
\hline $95 \% \mathrm{Cl}$ & $2 \cdot 6,2 \cdot 8$ & $1 \cdot 6,1 \cdot 7$ & \\
\hline Median & $2 \cdot 0$ & $1 \cdot 0$ & \\
\hline Q1, Q3 & $1 \cdot 0,4 \cdot 0$ & $0.5,2 \cdot 0$ & \\
\hline \multicolumn{4}{|c|}{ Diet soft drinks } \\
\hline Mean & $1 \cdot 2$ & $1 \cdot 6$ & $<0.001$ \\
\hline $95 \% \mathrm{Cl}$ & $1 \cdot 1,1 \cdot 2$ & $1 \cdot 5,1 \cdot 7$ & \\
\hline Median & 0.5 & $1 \cdot 0$ & \\
\hline Q1, Q3 & $0 \cdot 0,2 \cdot 0$ & $0.5,2.0$ & \\
\hline
\end{tabular}

*Differences in gender, number of parents in the household and parental education were analysed using the $\chi^{2}$ test; differences in beverage intake were analysed using the independent-samples $t$ test. 
The parents participating in 2008 had higher education than those participating in $2001(P<0 \cdot 001)$. In 2001, $42 \%$ of the parents had higher education, while $54 \%$ of the parents had higher education in 2008. Comparing 2001 and 2008 unadjusted group means, children in 2001 more often drank fruit juice $(3 \cdot 6 v \cdot 3 \cdot 4$ times/week, $P=0 \cdot 012)$, lemonade $(4.8 v .2 .5$ times/week, $P<0.001)$ and regular soft drinks (2.7 v. 1.6 times/week, $P<0.001$; Table 1 and Fig. 1). For diet soft drinks children reported a less frequent intake in 2001 than in $2008(1 \cdot 2 v .1 \cdot 6, P<0 \cdot 001)$.

Further, the frequency of beverage consumption based on data from 2001 and 2008 collectively was analysed according to differences in gender, parental education,

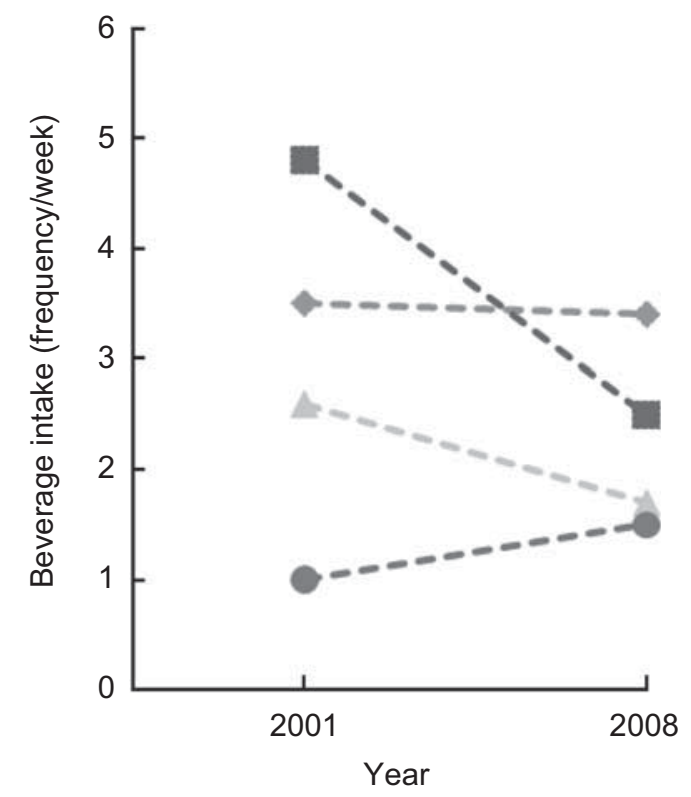

Fig. 1 Difference in beverage intake $(-\leftarrow--$, juice; $-\leftarrow-\infty$, lemonade; $=-\infty$, regular soft drinks; $--\infty$, diet soft drinks) between 2001 and 2008 (unadjusted data) among 6th and 7th grade Norwegian pupils, the Fruits and Vegetables Make the Marks (FVMM) project number of parents in the household (Table 2). Table 2 also presents differences in frequency of beverage consumption according to study year. Adjusting for gender, parental education level and the number of parents in household did not change the crude time trends for consumption frequencies of lemonade, regular soft drinks and diet soft drinks reported above. On the other hand, there were no significant differences in frequency of fruit juice consumption reported by children in 2001 and 2008 after adjusting for these variables. Girls reported to drink fruit juice more often compared with boys (3.6 v. 3.2 times/ week, $P=0 \cdot 002)$, whereas boys reported a more frequent intake of lemonade $(3.8 v .3 .5$ times/week, $P=0.003)$ and regular soft drinks $(2 \cdot 3 v .2 \cdot 0$ times/week, $P<0 \cdot 001)$ compared with girls. The present study showed no difference in intake frequency of diet soft drinks between boys and girls. Children with higher educated parents reported to drink fruit juice more often than children with lower educated parents $(3 \cdot 7 v .3 \cdot 2$ times/week, $P<0 \cdot 001)$. Children with lower educated parents reported a more frequent intake of lemonade $(3.8 v .3 .4$ times/week, $P=0.002)$, regular soft drinks $(2.4 v .1 .8$ times/week, $P<0.001)$ and diet soft drinks $(1 \cdot 4 v \cdot 1 \cdot 1$ times/week, $P<0 \cdot 001)$ than those with higher educated parents. The study showed no significant differences in frequency of beverage consumption between children living with single parents compared with those living with two parents.

For frequency of fruit juice consumption, significant interactions were observed between time and gender and between time and parental education (Table 3). Boys increased their frequency of fruit juice consumption (from $3 \cdot 1$ to $3 \cdot 3$ times/week) whereas girls decreased their frequency of fruit juice consumption (3.8 to 3.4 times/week; interaction time $\times$ gender $P=0 \cdot 02$ ). Further, children with higher educated parents increased their frequency of fruit juice consumption $(3 \cdot 6$ to $3 \cdot 8$ times/week) whereas those with lower educated parents decreased their frequency of fruit juice consumption $(3 \cdot 3$ to $3 \cdot 0$ times/week; interaction

Table 2 Adjusted mean frequency of beverage consumption per week according to gender, parental education, number of parents in the household and year the study was performed; 6th and 7th grade Norwegian pupils, the Fruits and Vegetables Make the Marks (FVMM) project

\begin{tabular}{|c|c|c|c|c|c|c|c|c|c|c|c|c|c|}
\hline & \multirow[b]{2}{*}{ Total $(n)$} & \multicolumn{3}{|c|}{ Juice } & \multicolumn{3}{|c|}{ Lemonade } & \multicolumn{3}{|c|}{ Regular soft drinks } & \multicolumn{3}{|c|}{ Diet soft drinks } \\
\hline & & Mean & $95 \% \mathrm{Cl}$ & $P^{*}$ & Mean & $95 \% \mathrm{Cl}$ & $P^{*}$ & Mean & $95 \% \mathrm{Cl}$ & $P^{*}$ & Mean & $95 \% \mathrm{Cl}$ & $P^{*}$ \\
\hline \multicolumn{14}{|l|}{ Gender } \\
\hline Boy & 1378 & $3 \cdot 2$ & $3 \cdot 0,3 \cdot 5$ & & $3 \cdot 8$ & $3 \cdot 6,4 \cdot 0$ & & $2 \cdot 3$ & $2 \cdot 1,2 \cdot 4$ & & $1 \cdot 3$ & $1 \cdot 2,1 \cdot 5$ & \\
\hline Girl & 1422 & 3.6 & $3 \cdot 4,3 \cdot 8$ & 0.002 & 3.5 & $3 \cdot 2,3 \cdot 7$ & 0.003 & $2 \cdot 0$ & $1 \cdot 8,2 \cdot 1$ & $<0.001$ & $1 \cdot 2$ & $1 \cdot 1,1 \cdot 3$ & $0 \cdot 14$ \\
\hline \multicolumn{14}{|c|}{ Parental education } \\
\hline Low & 1156 & $3 \cdot 2$ & $3 \cdot 0,3 \cdot 4$ & & $3 \cdot 8$ & $3 \cdot 6,4 \cdot 0$ & & $2 \cdot 4$ & $2 \cdot 2,2 \cdot 5$ & & $1 \cdot 4$ & $1 \cdot 3,1 \cdot 6$ & \\
\hline High & 1038 & $3 \cdot 7$ & $3 \cdot 5,3 \cdot 9$ & $<0.001$ & $3 \cdot 4$ & $3 \cdot 2,3 \cdot 7$ & 0.002 & $1 \cdot 8$ & $1 \cdot 7,2 \cdot 0$ & $<0.001$ & $1 \cdot 1$ & $1 \cdot 0,1 \cdot 2$ & $<0.001$ \\
\hline \multicolumn{14}{|c|}{ Parents in household } \\
\hline 1 & 531 & $3 \cdot 4$ & $3 \cdot 1,3 \cdot 7$ & & $3 \cdot 7$ & $3 \cdot 4,4 \cdot 0$ & & $2 \cdot 2$ & $2 \cdot 0,2 \cdot 4$ & & $1 \cdot 3$ & $1 \cdot 1,1 \cdot 5$ & \\
\hline$>1$ & 2197 & 3.5 & $3 \cdot 3,3 \cdot 6$ & $0 \cdot 48$ & 3.5 & $3 \cdot 3,3 \cdot 7$ & $0 \cdot 12$ & $2 \cdot 0$ & $1 \cdot 9,2 \cdot 2$ & $0 \cdot 16$ & $1 \cdot 3$ & $1 \cdot 2,1 \cdot 3$ & $0 \cdot 70$ \\
\hline \multicolumn{14}{|l|}{ Year } \\
\hline 2001 & 1488 & $3 \cdot 5$ & $3 \cdot 2,3 \cdot 7$ & & $4 \cdot 8$ & $4 \cdot 5,5 \cdot 0$ & & $2 \cdot 6$ & $2 \cdot 4,2 \cdot 7$ & & $1 \cdot 0$ & $0 \cdot 9,1 \cdot 2$ & \\
\hline 2008 & 1339 & $3 \cdot 4$ & $3 \cdot 1,3 \cdot 6$ & $0 \cdot 60$ & $2 \cdot 5$ & $2 \cdot 2,2 \cdot 7$ & $<0.001$ & $1 \cdot 7$ & $1 \cdot 5,1 \cdot 8$ & $<0.001$ & $1 \cdot 5$ & $1 \cdot 4,1 \cdot 7$ & $<0.001$ \\
\hline
\end{tabular}

*Multilevel linear mixed models adjusted for all variables presented for each model. 
time $\times$ parental education $P=0 \cdot 04$ ). The study showed no further differences in beverage consumption frequency according to gender, parental education and number of adults in household in this time period.

\section{Discussion}

In 2008, children reported a less frequent intake of fruit juice, lemonade and regular soft drinks, and a more frequent intake of diet soft drinks, than in 2001. These results from the present study confirm a trend in reduced consumption of SSB among Norwegians; after an increased consumption between 1989 and 2001, a subsequent decrease in regular soft drinks consumption has been reported between 2001 and 2007 in the general Norwegian population ${ }^{(25)}$. The Norwegian national study, Ungkost, showed a high intake of added sugar, with regular soft drinks as a major source among children and adolescents in 2000/2001 ${ }^{(1)}$. These nutritional challenges resulted in an increased focus from Norwegian health authorities on reducing the intake of sugar-sweetened foods and beverages among children and adolescents. The strategies developed due to national initiatives challenged school owners to prevent access to soft drinks and promote good access to cold drinking water. In addition, national authorities have increased taxes on SSB and claimed that marketing of unhealthy foods and beverages aimed at children and young people should be prohibited $^{(21,23)}$.

Most likely, the increased focus to reduce the total consumption of added sugar may partly explain the reduced frequency of consumption of added sugar from SSB since 2001. In 2007, a report from the Norwegian Scientific Committee for Food Safety ${ }^{(29)}$ concluded that replacing sugar with intense sweeteners in soft drinks may reduce the risk of weight gain. In addition, such a shift in beverage consumption will most probably reduce the incidence of caries. However, randomized controlled trials in children are very limited, and do not clearly demonstrate either beneficial or adverse metabolic effects of artificial sweeteners ${ }^{(30)}$.

In other countries within the same age group, and time period, an increase in SSB and fruit juice consumption has been reported. In Ireland, both the portion size consumed and the frequency of consumption of SSB increased significantly among adolescents in 2005 compared with those in $1997^{(31)}$. Over the past few decades, consumption of SSB and fruit juice has increased considerably among children, adolescents and adults in the USA $^{(32-34)}$. These dietary changes for SSB and fruit drinks have been explained by: (i) an increased proportion of persons of all ages consuming these beverages; (ii) the portion sizes have increased; and (iii) the number of servings has increased ${ }^{(34)}$.

The present study showed that gender influenced the frequency of beverage consumption; boys reported to 
drink SSB including lemonade and regular soft drinks more often than girls. On the other hand, girls reported to drink fruit juice more often than boys. A study by Vågstrand et $a l^{(17)}$ showed a significantly higher intake of soft drinks and fruit juices among boys compared with girls. In this latter mentioned study, soft drinks and fruit juice consumption were associated with each other but with opposite direction in Swedish boys and girls ${ }^{(17)}$. The association was negative in boys and positive in girls $(P=0.04$ for interaction). In addition, several other studies have reported that boys tend to drink more soft drinks than girls ${ }^{(16-18)}$. From 2001 to 2008, the differences in frequency of fruit juice consumption were significantly different between genders in the present study; boys reported a more frequent intake whereas girls reported a less frequent intake of fruit juice. The Norwegian Directorate of Health ${ }^{(6)}$ has focused on decreasing the intake of added sugar and increasing the intake of vegetables, fruits and berries, including fruit and vegetable juices, among children and adolescents. However, it is interesting to notice that the present study shows that the consumption of fruit juice was significantly reduced from 2001 to 2008 due to a reduced consumption of fruit juice among girls. The reduced frequency of fruit juice intake among girls may be due to an increased consciousness and a rejection of energy-containing beverages, including naturally occurring carbohydrates. This potential relationship has not, to our knowledge, been studied.

An additional finding in the present study was the considerable variation in beverage consumption by parental educational level. More children with high educated parents reported high rates of fruit juice intake and low rates of lemonade, regular and diet soft drinks compared with children with low educated parents. In addition, children with higher educated parents drank fruit juice more often in 2008 than 2001, compared with children with lower educated parents. The differences in fruit juice consumption according to parental educational level may indicate that the introduced policy has increased social disparities. The Norwegian Hunt study recently confirmed that higher levels of parental education, in particular the mother's education, are clearly associated with lower prevalence odds ratio for drinking soft drinks daily ( $2 \cdot 5$ for girls and 1.9 for boys $)^{(16)}$. Other studies have also reported that lower social status, measured as parental occupation or education plan of the child, seems to be associated with a higher intake of soft drinks ${ }^{(4,35)}$. Several studies of children and adolescents have reported an association between higher levels of parental education and healthier dietary habits among children and adolescents ${ }^{(16,36)}$.

This social patterning should be recognized when planning future public health strategies. Thus, vulnerable health groups, specifically young boys and male adolescents, should be targeted in interventions to reduce intake of SSB.

The present study showed no significant differences in the consumption frequency of juice, lemonade, regular soft drinks and diet soft drinks among children according to number of parents in the household. Previously published research has not focused on family structure and beverage intake among children and adolescents. However, Stewart and Menning ${ }^{(28)}$ reported that adolescents living in non-traditional families were more likely than adolescents living with two biological/adoptive parents to display unhealthy eating habits.

The strengths of the present study are that it comprises two cross-sectional surveys in a well-defined population and includes a high number of participants, covering a time span from 2001 to 2008 from the same region. Our research has some limitations. First, the variables of soft drink and lemonade consumption frequency have not been validated. However, the test-retest reliability of juice, lemonade and soft drink consumption frequency has been reported to be acceptable (see 'Materials and methods' section). Second, the questionnaire used in the study did not have information on volume obtained from beverages. Third, the participating pupils were from two of Norway's nineteen counties only, and no large cities are situated in these two counties. However, Oslo is the only large city in Norway ( $>250000$ inhabitants), and as Norway in general is a rather homogeneous country we believe the results are likely to be generalizable to the other counties as well.

\section{Conclusions}

The present study shows a reduced consumption frequency of fruit juice, lemonade and regular soft drinks and an increased consumption frequency of diet soft drinks between 2001 and 2008. Gender and parental education seem to affect beverage choices, and boys living with lower educated parents are clearly an important target group for intervention strategies aimed at improving beverage choices.

\section{Acknowledgements}

The study was funded by the Norwegian Research Council. The authors declare that they have no competing interest. K.-I.K. conceived the FVMM project. E.B. designed the present study and E.B., T.H.S. and N.C.Ø. interpreted the data. T.H.S. and N.C.Ø. analysed the data and drafted the manuscript, and E.B. and K.-I.K. revised it critically. All authors have approved the final version of the manuscript.

\section{References}

1. Øverby N \& Andersen L (2002) Ungkost 2000. Landsomfattende kostholdsundersøkelse blant elever $i$ 4.- og 8. klasse $i$ Norge. Oslo: Directorate for Health and Social Affairs.

2. Lande B \& Andersen L (2005) Kosthold blant 2-åringer. Landsomfattende kostholdsundersøkelse - Småbarnskost. Oslo: Directorate for Health and Social Affairs. 
3. Øverby N, Lillegaard I, Johansson L et al. (2004) High intake of added sugar among Norwegian children and adolescents. Public Health Nutr 7, 285-293.

4. Bere E, Glomnes ES, te Velde SJ et al. (2008) Determinants of adolescents' soft drink consumption. Public Health Nutr 11, 49-56.

5. Marshall TA, Eichenberger Gilmore JM, Broffitt B et al. (2005) Diet quality in young children is influenced by beverage consumption. J Am Coll Nutr 24, 65-75.

6. The Norwegian Directorate for Health and Social Affairs (2005) Norwegian Recommendations for Nutrition and Physical Activity. Oslo: The Norwegian Directorate for Health and Social Affairs.

7. The National Council of Nutrition (2010) Kostråd for $a$ fremme folkehelsen og forebygge kroniske sykdommer $i$ Norgerapportutkast. Oslo: The National Council of Nutrition.

8. Malik VS, Schulze MB \& Hu FB (2006) Intake of sugarsweetened beverages and weight gain: a systematic review. Am J Clin Nutr 84, 274-288.

9. Marshall TA, Levy SM, Broffitt B et al. (2003) Dental caries and beverage consumption in young children. Pediatrics 112, e184-e191.

10. Pereira SM, Tagliaferro EP, Pardi V et al. (2010) Sugar consumption and dental health: is there a correlation? Gen Dent 58, e6-e12.

11. Nissinen K, Mikkilä V, Männistö S et al. (2009) Sweets and sugar-sweetened soft drink intake in childhood in relation to adult BMI and overweight. The Cardiovascular Risk in Young Finns Study. Public Health Nutr 12, 2018-2026.

12. Nguyen S, Choi HK, Lustig RH et al. (2009) Sugarsweetened beverages, serum uric acid, and blood pressure in adolescents. J Pediatr 154, 807-813.

13. Fung TT, Malik V, Rexrode KM et al. (2009) Sweetened beverage consumption and risk of coronary heart disease in women. Am J Clin Nutr 89, 1037-1042.

14. Schulze MB, Manson JE, Ludwig DS et al. (2004) Sugarsweetened beverages, weight gain, and incidence of type 2 diabetes in young and middle-aged women. JAMA $\mathbf{2 9 2}$, 927-934.

15. Odegaard AO, Koh WP, Arakawa K et al. (2010) Soft drink and juice consumption and risk of physician-diagnosed incident type 2 diabetes: The Singapore Chinese Health Study. Am J Epidemiol 171, 701-708.

16. Nilsen SM, Krokstad S, Holmen TL et al. (2010) Adolescents' health-related dietary patterns by parental socioeconomic position, The Nord-Trondelag Health Study (HUNT). Eur J Public Health 20, 299-305.

17. Vågstrand K, Linnè Y, Karlsson J et al. (2009) Correlates of soft drink and fruit juice consumption among Swedish adolescents. Br J Nutr 101, 1541-1548.

18. Verzeletti C, Maes L, Santinello M et al. (2009) Soft drink consumption in adolescence: associations with foodrelated lifestyles and family rules in Belgium Flanders and the Veneto Region of Italy. Eur J Public Health 20, 312-317.

19. Pearson N, Biddle S \& Gorely T (2009) Family correlates of fruit and vegetable consumption in children and adolescents: a systematic review. Public Health Nutr 12, 267-283.
20. Ministry of Health and Care Services (2007) Norwegian Action Plan on Nutrition (2007-2011) - Recipe for a healthier diet'. Oslo: Norwegian Ministries.

21. The Norwegian Consumer Council (2007) Retningslinjer for markedsføring av mat og drikke rettet mot barn og unge. Oslo: The Norwegian Consumer Council.

22. World Health Organization (2010) World Health Assembly agenda item A63/12. Includes Annex: set of recommendations on the marketing of food and non-alcoholic beverages to children. http://apps.who.int/gb/ebwha/pdf_ files/WHA63/A63_12-en.pdf (accessed May 2011).

23. The Norwegian Directorate of Health (2009) The Norwegian Directorate of Health's Annual Report on Measures to Reduce Social Inequalities in Health. Norwegian Public Health Policy Report 2009. Oslo: The Norwegian Directorate of Health.

24. The Norwegian Directorate of Customs and Excise (2010) Avgift på alkoholfrie drikkevarer mv. 2010. Rundskriv nr. 4. Oslo: The Norwegian Directorate of Customs and Excise.

25. The Norwegian Directorate of Health (2008) Norwegian Dietary Trends. Oslo: Norwegian Directorate for Health.

26. Andersen LF, Øverby N \& Lillegaard ITL (2003) Er det forskjell på hva barn spiser på hverdager og I helgen? Barn 2-3, 89-98.

27. Andersen LF, Bere E, Kolbjornsen N et al. (2004) Validity and reproducibility of self-reported intake of fruit and vegetable among 6th graders. Eur J Clin Nutr 58, 771-777.

28. Stewart SD \& Menning CL (2009) Family structure, nonresident father involvement, and adolescent eating patterns. J Adolesc Health 45, 193-201.

29. Andersen LF, Husøy T, Kolset SO et al. (2007) Impact on Health When Sugar is Replaced with Intense Sweeteners in Soft Drinks, 'Saft' and Nectar. Oslo: Norwegian Scientific Committee for Food Safety.

30. Brown RJ, de Banate MA \& Rother KI (2010) Artificial sweeteners: a systematic review of metabolic effects in youth. Int J Pediatr Obes 5, 305-512.

31. Kerr MA, Mccrorie TA, Rennie KL et al. (2009) Snacking patterns according to location among Northern Ireland children. Int J Pediatr Obes 5, 243-249.

32. Bleich SN, Wang YC, Wang Y et al. (2009) Increasing consumption of sugar-sweetened beverages among US adults: 1988-1994 to 1999-2004. Am J Clin Nutr 89, 372-381.

33. Duffey KJ \& Popkin BM (2007) Shifts in patterns and consumption of beverages between 1965 and 2002. Obesity (Silver Spring) 15, 2739-2747.

34. Nielsen SJ \& Popkin BM (2004) Changes in beverage intake between 1977 and 2001. Am J Prev Med 27, 205-210.

35. Vereecken C, Inchley J, Subramanian S et al. (2005) The relative influence of individual and contextual socioeconomic status on consumption of fruit and soft drinks among adolescents in Europe. Eur J Public Health 15, 224-232.

36. Rasmussen M, Krølner R, Klepp KI et al. (2006) Determinants of fruit and vegetable consumption among children and adolescents: a review of the literature. Part I: quantitative studies. Int J Behav Nutr Phys Act 3, 22. 